\title{
Multi-site Utvärdering och Forskning
}

\author{
Edward Mullen ${ }^{1}$
}

\begin{abstract}
Denna artikel undersöker multi-site utvärdering och forskning och anger hur denna skiljer sig från single-site forskning och utvärdering. Författaren visar på olika former och typer av multi-site forskning för att illustrera varierande tillämpningar. Artikeln presenterar exempel på multi-site forskning som utförts i USA, på nationell nivå, med referens till mentalhälsoservice och behandling av alkoholmissbruk. Ytterligare exempel är hämtade från mentalhälsovård, barnavård och praktiskt socialt arbete och den forskning som utförts vid Center for the Study of Social Work Practice in New York City. Fördelar och nackdelar med multi-site forskning diskuteras liksom förslag på hur forskningen ska genomföras.
\end{abstract}

Nyckelord: multi-site forskning, multi-site utvärdering, forskningsledning, forskningsmetod, forskningsanvändning, forskningstillämpning, klinisk forskning.

\footnotetext{
${ }^{1}$ Edward J Mullen, B.A., M.S.W., D.S.W.; Willma \& Albert Musher Chair Professor for Life Betterment through Science and Technology, Columbia University School of Social Work; Director, Center for the Study of Social Work Practice, a joint program of Columbia University School of Social Work \& the Jewish Board of Family \& Children's Services; Director, NIMH funded PhD Training Program in Mental Health Services Research. Mailing address: Columbia University School of Social Work, $622 \mathrm{~W} 113^{\text {th }}$ Street, New York, NY, 10025; email ejm3@columbia.edu. The assistance of Haluk Soydan, Gretchen Borges, and Chito Trillana in the preparation of the original paper is acknowledged.
} 


\section{Introduktion}

Denna artikel undersöker multi-site utvärdering och forskning ${ }^{\mathrm{i}}$ och hur denna skiljer sig från single-site forskning. I denna artikel undersöker jag former och typer av multi-site forskning för att illustrera varierande tillämpningar. Jag beskriver multi-site forskning i USA, på nationell nivå, med referens till mentalhälsoservice och behandling av alkoholmissbruk. Baserat på mina erfarenheter som forskningsledare för ett center för forskning i socialt arbete, the Center for the Study of Social Work Practice (CSSWP), beskriver jag ytterligare tillämpningar inom mentalhälsovård, barnavård och praktiskt socialt arbete. ${ }^{\text {ii }}$ Jag sammanfattar mina reflektioner om fördelar och nackdelar av multisite forskning och skisserar förslag till själva utförandet av multi-site forskning.

Lite har skrivits om metodologin när det gäller multi-site forskning. Det finns dock undantag. En informativ artikel på franska av Irene Elkin skrevs 1992 och baserades på hennes 10 år långa erfarenhet som koordinator vid the U.S. National Institute of Mental Health (NIMH) Treatment of Depression Collaborative Research Program (Elkin, 1992). Publikationer baserade på erfarenheter från projekt MATCH, en multi-site studie för att undersöka alternativa behandlingar av alkoholism, är ett annat viktigt bidrag (Fuller et al, 1994; Friedman, 1982; Zweben et al, 1994; Del Boca, 1994). Ett annat informativt paper har framställts av Robert Boruch och Ellen Foley, planerat att ingå i en bok editerad av Leonard Bickman (Boruch och Foley, under utarbetande). Boruch, Foley och Jeremy Grimshaw har också undersökt en typ av multi-site utvärderingsforskning i en artikel som ingår i detta nummer av Socialvetenskaplig Tidskrift. Det framstår dock som om det råder brist på publicerade analyser av multi-site forskning och utvärderingsmetoder. Även om multi-site studier har blivit vanliga under 
senare år verkar det samtidigt ha funnits ett antagande om att det är tillräckligt att följa de metoder, som utvecklats för användning i single-site forskning. Som ett resultat av detta har misstag blivit begångna och möjligheter har gått förlorade i många av de multisite studier, som tidigare utförts.

Många är de frågor som behöver undersökas, när det gäller multi-site forskning. Vad är multi-site forskning? Varför utföra multi-site forskning? Vad står att vinna genom multi-site studier? Vad förloras genom multi-site undersökning? Vilka infrastrukturer behövs för att framgångsrikt kunna implementera multi-site undersökningar? När NIMH Treatment of Depression Collaborative Research Program blev påtänkt, så noterar Elkin (1992) att en rad viktiga frågor ställdes, frågor som är viktiga att fundera över mer generellt, när multi-site forskning skall igångsättas: Skulle det vara möljligt att få tag i forskare som var villiga att åtaga sig ett längre samarbete över tid? Skulle det vara möjligt för enskilda forskare att sätta sin egen forskning i andra hand i förhållande till de gemensamma generella målen? Skulle det vara möjligt att uppnå enighet helt generellt mellan olika platser, så att studien kan betraktas som en reproduktion över platser? Skulle det vara möjligt att bibehålla forskningsgruppens intresse och engagemang under ett sådant långt åtagande? Skulle det vara möjligt att i samarbete dokumentera, analysera och tolka och upptäckterna på ett ömsesidigt och tillfredsställande sätt? Skulle en samarbetsinriktad multi-site modell visa sig givande och överlägsen självständiga single-site studier vad beträffar slutsatser om effektiviteten av behandlingar?

Inom vissa forskningsområden har multi-site studier blivit allt vanligare. Beroende av kostnader - när det gäller tid, pengar och personal - (se Fuller et al, 1994), 
har emellertid multi-site studier endast utförts efter det att preliminära data eller hänsyn till vissa riktlinjer visat på behovet av ett större representativt urval. Enligt Fuller et al (1994) har tilldelning av medel följt denna trend. The United States National Cancer Institute och the National Eye Institute stöder nästan uteslutande multi-site studier och ungefär hälften av de kliniska försöksstudierna vid the National Heart, Lung, and Blood Institute är multi-site studier. Andra enheter inom United States' National Institutes of Health, såsom the National Institute of Mental Health och the National Institute on Alcohol and Alcoholism, uppmuntrar i ökande omfattning kooperativ eller samverkande forskning, som omfattar flera sites (ung. platser). Enligt Elkin är samverkande multi-site forskning i stor skala inte något nytt inom fältet vad gäller forskning om mental hälsovård. Denna typ av forskning har kallats collaborative clinical trials. Medan samverkande kliniska försök har blivit vanliga inom psykofarmakologi och olika medicinska områden har dess användning under många år varit relativt sparsam inom psykoterapi och forskning i socialt arbete (Elkin, 1992). Likaledes har, enligt Fuller et al (1994) i deras diskussioner om Project MATCH, multi-site kliniska försök använts i medicin och psykiatri under en tid, men först nyligen har de börjat användas i forskning om behandling av alkoholism.

\section{Skillnader mellan multi-site och single site- forskning}

Vad skiljer single-site och multi-site forskning åt? Den mest uppenbara skillnaden är den geografiska. Single-site studier utförs på en geografisk plats. Multisite forskning utförs på mer än en plats.

\section{Single-site forskning}


I single-site forskning tas de studerade platserna från området. Generalisering uppnås genom upprepning vid samma plats och vid användning av olika prov eller underpopulationer. Likaså uppnås generaliserbarhet och extern validitet genom påföljande upprepning vid andra geografiska platser. Upprepade studier strävar efter att använda identiska eller åtminstone liknande metoder. Upprepningar fokuserar på samma frågor och variabler som i originalstudien. Emellertid är efterföljande singe-site upprepningar ofta omkonstruerade. Som ett resultat av omkonstruktionerna är de ursprungliga forskningsfrågorna såväl som originalstudiens variabler oftast förändrade baserat på vad som kommit fram i tidigare single-site applikationer. Det är kanske bättre att betrakta efterföljande single-site studier som utveckling eller specificering av tidigare studier i ett forskningsprogram, eftersom målet ofta inte är upprepning utan snarare tillämpning med olika undertester, i olika miljöer, organisationella kontexter etc. Detta senare mål eftersträvas som ett försök att påskynda slutsaterna. Sådana program med progressiva single-site studier kan skadas av många misslyckade upprepningar till följd av de kontinuerliga modifikationer som äger rum. Dessutom kan sägas att medan moderna metoder av meta-analys har utvecklats, som tillåter samlad analys av data från multiple single-site studier när sådana single-site studier är kombinerade i metaanalytiska granskningar, uppnås lägre säkerhet än vad som blir fallet med säkra samverkande upprepningar som resulterar från multi-site undersökningar.

Single-site utvärderingsstudier innehåller ofta små testmängder till följd av begränsningar i tillgången på hur många subjekt som finns tillgängliga vid varje given geografisk plats. ${ }^{\text {iii }}$ Det är till exempel mitt intryck att detta kan vara fallet i Sverige där man i studier som utförts i en kommun kan ha en inbyggd begränsning när det gäller testmängd. Olyckligtvis är detta ofta också fallet när det gäller upprepningar av single- 
site studier i andra områden, som drabbas av samma begränsning till följd av att små testmängder används återkommande. Upprepad användning av serier av små testmängder kan inte överbrygga de problem som är förbundna med forskning på små testmängder.

\section{Multi-site forskning: Ett försök till klassifikation av multi-site forskning}

Multi-site studier använder mer än en geografisk plats inom kontexten. Till skillnad från single-site studier kan multi-site studier öka teststorleken genom att hämta information från mer än en plats. Antalet platser kan väljas med hänsyn till statistisk styrka. ${ }^{\text {iv }}$ Detta betyder att för att uppnå en önskad statistisk styrka kan planläggningen göras utifrån hur stort testet behöver vara, hur många subjekt som kan göras tillgängliga på varje plats och även hur många platser som krävs. Detta utgör ett betydande fördel jämfört med single-site studier, som var och en är begränsad till platsens bundenhet. Likaså kan multi-site studier, till skillnad från single-site studier, möjliggöra upprepningar om sådana är önskvärda. Multi-site studier som inkluderar planer på upprepningar kan använda identiska eller nära nog identiska tillvägagångssätt på olika platser och därigenom minska eventuell förekomst av variationer i utfallet. Om forskningen dessutom utförs samtidigt vid olika platser kan förbryllande temporära skillnader minimeras. Om avsikten är upprepningar vid multiple sites, kan naturligtvis ansträngningar göras för att säkra att alla andra platsrelaterade förhållande är lika, som testkaraktäristika. När det gäller interventionsstudier skulle multiple site upprepningar behöva inkludera speciella förberedelser för att säkra att interventionerna administrerades på liknande sätt vid de olika platserna. 
Ibland är avsikten i multi-site studier inte upprepning utan snarare att undersöka variationer över testkaraktäristik eller tillvägagångssätt för att underlätta vidareutveckling och specifikation. I sådna fall kan till exempel platser med olika populationer sökas för att studera effekterna av en intervention i populationer med olika etnisk sammansättning .

\section{Tre former av multi-site forskning}

Inga klassifikationer för multi-site forskning har accepterats rent generellt. Elkin noterar att det förekommer minst tre modeller (Elkin, 1992). Dessa modeller reflekterar olika roller som individuella forskare kan ha i förhållande till centralt beslutsfattande. Elkin beskriver dessa modeller enligt följande: (1) centralt utformade och koordinerade modeller med platser som utvalts i konkurrens genom att ha granskats av medarbetare som i varierande grad är involverade i beslutsfattande; (2) modeller där forskare själva bestämmer att samarbeta och redan från starten tillsammans utformar ett gemensamt tillvägagångssätt; (3) modeller där forskare använder gemensamma databaser men inte samarbetar i implementeringen av studien.

Jag finner det användbart att skilja mellan följande former av multi-site forskning: simple multi-site research, complex multi-site research och multi-site allocation research. I det följande skall jag kort beskiva var och en av dessa former genom att ge exempel från våra erfarenheter vid CSSWP och från annan forskning som utförts i USA. Beskrivningarna får av nödvändighet här bli korta och endast belysa multi-site dimensioner. Vidare kommer inget försök att göras för att presentera framsteg eller slutsatser. Den intresserade läsaren rekommenderas ta del av de listade referenserna för ytterligare information och slutsatser som hänför sig till respektive studie. 


\section{Simple multi-site forskning}

Ofta används samma forskningsfrågor och samma tillvägagångssätt vid platserna. Jag kommer att benämna dessa som simple multi-site studier. Dessa skiljer sig från de jag benämner complex multi-site studier vilka hänför sig till olika forskningsfrågor och/eller använder olika tillvägagångssätt vid de platser som studeras. Jag ger två exempel, det första är mer detaljerat eftersom det är det första exemplet på multi-site forskning och är taget från våra erfarenheter från CSSWP. Det andra är en välkänd multi-site studie stödd av U.S. National Institute of Mental Health (NIMH).

\section{Från forskning till praktik}

Från forskning till praktik är ett exempel på enkel multi-site studie som nyligen slutförts vid CSSWP i samarbete med forskare vid New York State Psychiatric Institute (NYS-PI). Det är ett exempel på enkel multi-site studie därför att en enkel uppsättning av forskningsmål, frågor, hypoteser och gemensamt tillvägagångssätt, använts vid samtliga forskningsplatser. En multi-site studie, snarare än en singe-site studie, indikerades för att öka testmängden utöver vad som kunde uppnås vid varje given plats och för att öka den geografiska och demografiska mångfalden i den samplade patientpopulationen.

Studien leddes av en forskningsledare (Principal Investigator) tillsammans med två medverkande forskare vid samordnande avdelningen, NYS-PI. Forskningsledaren vid NYS-PI fick stöd från NIMH via New York State Research Foundation for Mental Hygiene. ${ }^{v}$ Studien utarbetades av forskningslaget vid NYS-PI. Detta forskarlag hade det löpande ansvaret för projekkoordination, utförande, datanalys och rapportering. I den ursprungliga planen ingick ett underkontrakt med ett forskarlag i New Jersey och ett 
New York City-baserat CSSWP forskarlag. I New Jersey gällde uppgifterna en poliklinik för mental hälsa. I New York City utfördes forskningen av CSSWP. I New York City ingick åtta kommunbaserade polikliniker för mental hälsa som drevs av Jewish Board of Family and Children's Services (JBFCS). Dessa kliniker finns i fyra av stadens fem stadsdelar.

Varje underkontraktör hade en utsedd forskningsledare och forskningspersonal. Varje underkontraktör hade ansvar för pojektets utförande vid sina respektive enheter inklusive granskning och godkännande av de deltagande personerna, administration och insamling av data. Publiceringen av vad som kom fram i studierna och kunde hänföras till en plats var ett gemensamt ansvar för forskningsledaren vid NYS-PI och den forskningsledare som fanns vid den underkontakterade enheten.

Från forskning till praktik undersökte hur ett datoriserat, diagnostiskt bedömningsinstrument för mental hälsa, the Computerized Diagnostic Interview Schedule for Children (C-DISC), ursprungligen framtaget för att användas i epidemiologisk forskning, påverkar klinisk praktik vid användning på barn och ungdomar i poliklinisk behandling. C-DISC upplägget är administrerat, datoriserat, intervjubaserat på American Psychiatric Association’s Diagnostic and Statistical Manual for Mental Disorders, version IV (DSM-IV), och den tionde upplagan av World Health Organization's (WHO) International Classification of Diseases (ISD-10). Som ursprungligen planerats, skulle utvärderingen använda en experimentell design. På varje klinik skulle data insamlas under en tidsperiod, som skulle visa den normala praktiken vid varje klinik före försöksverksamheten. Efter denna prospekteringsperiod vid varje klinik, skulle hälften av alla kliniker slumpmässigt utväljas och utsättas för C-DISC. 
Den andra hälften skulle fortsätta sin rutinmässiga praktik och fylla i en kontrollista för datainsamling. Efter ett år skulle klinikerna i vardera av dessa båda försök skifta plats för att få något som kallas crossover design (Mullen, 1998; Mullen et al., under utarbetande).

\section{NIMH Treatment of Depression Collaborative Research Program (simple - intervention)}

NIMH Treatment of Depression Collaborative Research Program är ett annat exempel på en simple multi-site studie. Studien som utfördes samtidigt vid ett flertal forskningsplatser (University of Pittsburgh, George Washington University, Washington D.C. och the University of Oklahoma), innehöll en vanlig uppsättning forskningsfrågor och en vanlig forskningsmetod. Studien krävde visst samarbete mellan forskningsplatserna och dessutom utbildningsplatser vid NIMH and the Veterans Administration Data Analysis Facility (Veterans Administration Hospital, Perry Point, Maryland).

Studien använde en försöksmodell i vilken behandling slumpmässigt tilldelades patienterna. Det grundläggande målet för denna NIMH-stödda samarbetsforskningen var att bedöma verkan, effektivitet och säkerhet av två väl definierade angrepssätt för psykologisk korttidsbehandling, kognitiv/beteendeterapi och interpersonell psykoterapi för poliklinikpatienters behandling av non-bipolar, non-psychotic depression. Dessa två terapier jämfördes med en medicinbehandling som tidigare visat sig vara effektiv för den studerade populationen. Dessutom inkluderades tablett-placebo. Resultaten som uppmättes var symptomatologi, generell klinisk status och social funktion. Dessa mätningar gjordes vid varierande tillfällen under behandlingstiden, vid behandlingstidens slut och vid flera uppföljningstillfällen (Elkin, 1994). 


\section{Komplex multi-site forskning}

En multi-site studie kan ha gemensamt antal mål, men inom dessa gemensamma mål kan olika forskningsfrågor undersökas på olika platser. Likaledes kan olika tillvägagångssätt användas vid olika platser, specifikt till de frågor som ställs vid olika platser. Sådana försök anses vara multi-site studier eftersom de är en planerad komponent $\mathrm{i}$ ett större forskningssammanhang som är fokuserat på ett specifikt antal mål. Jag vill kalla dessa complex multi-site studier, med referens till den grad av komplexitet som forskningsfrågorna har och till de tillvägagångssätt som används. Två sentida exemple på complex multi-site forskning är Matching Patients to Alcoholism Treatments (Project MATCH) och Mental Health Service Use, Needs, Outcomes, and Costs in Child and Adolescent Populations (UNOCCAP).

\section{Matching Patients to Alcoholism Treatments - Projekt MATCH}

Projekt MATCH är ett exemple på complex multi-site forskning. Detta var ett multi-site matching klientbehandlingsförsök som involverade nio geografiskt olika kliniker och ett koordinationscenter. Studien finansierades av United States National Institute on Alcohol Abuse and Alcoholism. Avsikten med Project MATCH var att bedöma fördelarna med att matcha alkoholberoende klienter med tre olika behandlingar och med referens till varierande klientegenskaper. Detta är ett exempel på en complex multi-site studie eftersom två parallella men oberoende slumpmässiga kliniska försök utfördes, ett med alkoholberoende klienter i poliklinisk terapibehandling vid fem platser och ett med klienter i efterbehandling som erhöll terapi efter att ha varit inlagda eller att ha varit dagpatienter vid fyra platser. Klienterna tilldelades slumpvis ett av tre tolvveckors, manual-styrt, individuellt utfört behandlingsprogram: Cognitive Behavioral Coping Skills Therapy; Motivational Enhancement Therapy; or, Twelve-Step 
Facilitation Therapy. Klienterna följdes sedan i ett år under efterbehandlingsperioden. Dessutom gjordes en uppföljdningsstudie efter tre år. Individuella skillnader på hur man svarat på behandlingen utvärderades för 10 primärt matchande variabler och 16 kontrastspecificerade $a$ priori. Grundläggande resultatmätningar var procent dagar av abstinens och antal drinkar per dryckesdag (Project MATCH Research Group, 1997).

\section{Mental health service use, need, outcomes, and costs in child and adolescent populations (UNOCCAP)}

Ett annat forskningsprogram var Multi-site Study of Mental Health Service Use, Need, Outcomes, and Costs in Child and Adolescent Populations, kallat UNOCCAP studien. Även om forskningsprogrammet $U N O C C A P$ avbröts efter utvecklingsfasen, kan det tjäna som ett bra exempel på en storskalig, komplex multi-site forskning. 1994 efterlyste NIMH ansökningar, i kooperativ överenskommelse, för en femårsstudie av mental hälsoservice för barn och ungdom. De önskade ansökningar för två typer av studier. En var en multi-site, samarbetsinriktad, longitudinell studie på kommunal nivå av barn och ungdomars användning av mental hälsoservice, omfattningen av bristfällig eller otillräcklig service och på vilket sätt organisering och finansiering av service påverkar tillgång, användning och utfall av mental hälsoservice. Den andra studien var en nationell undersökning om förekomst och frekvens av specifik mental störning hos barn och ungdom, nyttjande av mental hälsoservice över större servicesektorer samt kostnader och finansiering av vård. Initiativet från UNOCCAP uppmuntrade och efterfrågade samverkan av multidisciplinära forskarlag både kommunalt och nationellt och strävade efter att oberoende undersökningsteam skulle arbeta tillsammans för att utveckla gemensamma tillvägagångssätt. Detta finaniserades av National Institutes of Health (NIH). Personalen vid National Institute of Health (NIMH) arbetade tillsammans 
med anslagstagarna i partnerskap, för att stödja, koordinera och underlätta deras verksamhet, och för att hjälpa studien genom dess olika faser. Överinseende och huvudansvar för utförande och implementation låg hos anslagsinnehavarna.

De platser som deltog vid UNOCCAP var Johns Hopkins University, University of California at Los Angeles, University of Chicago, och Washington University, med stöd även från Research Triangle Institute, Rand Corporation, Vanderbilt University, Yale University, och personalen vid NIMH. NIMH budgeterade 45 miljoner dollar för projektet över fem år, vilket också erhöll stöd från the United States Administration for Children, Youth and Families; the United States National Institute of Child Health and Human Development; the United States Substance Abuse and Mental Health Services Administration; the United States Department of Education; and, the MacArthur Foundation.

Ursprungligen föreställde man sig att $U N O C C A P$ skulle kunna ge både nationella exempel på sannolikheten för att fastställa prevalens och frekvens av specifika störningar hos barn, och en uppsättning av studier på kommunal nivå för att undersöka typ och mönster av mental hälsoservice som används av barn och ungdom, brist på service samt finansieringen. Under utvecklingsfasen på två år av UNOCCAP -studien, tog forskarna fram ett nationellt urval av ungefär 10000 barn och ungdomar, och gjorde stora ansträngningar för att utveckla mätmetoderna. Samarbetsparterna planerade även att bedöma ytterligare sampling av barn både vid polikliniker, såsom speciell mental hälso- och skolbaserad service, och patientservice.

Studien blev föremål för en vetenskaplig granskning 1997 av en panel (Oversight Board) som tillsattas av direktören för NIMH. Baserat på panelens rekommendationer beslutades att UNOCCAP- studien ej skulle genomföras. Jag återkommer till denna 
studie i min slutkommentar eftersom den illusterar vissa saker som är viktiga när det gäller utförandet av multi-site forskning (National Institute of Mental Health, 1998).

\section{Multi-site allocation forskning}

Multi-site allocation forskning skiljer sig tydligt från simple och complex multisite forskning. I denna tredje form av multi-site studie är den geografiska enheten inte använd som bestämd plats för studien, utan istället är det den geografiska enheten som är föremål för studien. Följaktligen beskriver Boruch and Foley "sites and other entities, rather than individuals, as the units of allocation, treatment and analysis" i slumpvisa försök (Boruch \& Foley, 2000). Platserna de beskriver är geografiska platser som används som allokeringsenheter. Andra exempel på allokeringsenheter är familjer, kommuner och organisationer. De fokuserar på experimentell forskning i vilken platser och enheter slumpmässigt tilldelas olika interventioner för att studera kausala samband. Platser kan emellertid även studeras i icke slumpmässig forskning såväl som i slumpmässig forskning. Jag refererar till denna form av multi-site studie som multi-site allocation oavsett om den använder en slumpmässig eller icke slumpmässig design. Slumpmässiga allocation studier diskuteras av Boruch med flera i en annan artikel i denna tidskrift. I det följande ger jag ett exempel från vårt arbete vid SSWP, nämligen Sanctuary studien.

\section{Trauma Focused Intervention Targeting Risk for Violence (Sanctuary)}

Denna multi-site interventionsstudie är utförd av CSSWP vid tolv JBFCS behandlingsprogram för barn och ungdom som drivs i Westchester County, New York.

De tolv internatenheterna tilldelas slumpmässigt antingen en innovativ miljöbehandling eller en ordinarie internatbehandling utan det innovativa förhöjande inslaget. Denna multi-site forskning undersöker implementation och proximal effekt av en intervention 14 
designad för att reducera traumarelaterade symptom hos ungdomar som leder till ökad risk för våldsamt beteende, dålig anpassning och allvarliga svårigheter när det gäller deras mentala hälsa.

Målen uppnås genom att använda en 2 x 5 design. Två villkor är här uppfyllda nämligen det experimentella Sanctuary Model, den förstärkta miljöbehandlingen eller Standardized Residential Services, som är den ordinarie behandlingen. För att mäta resultatet tas variabler vid fem datainsamlingspunker, vid baslinjen, vid tre månader, vid sex månader, vid nio månader och vid 12 månader. De tolv internatenheterna har slumpmässigt tilldelats antingen Sanctuary Model eller Standard Residential Services. De tolv inernatenheterna har 150 ungdomar och 96 anställda. Implementeringen och effekter av modellen mäts på behandlarnivå (dvs uppfattade förändringar i den terapeutiska miljön, förändringar i interaktionsmönstret mellan personal och ungdomar) och på ungdomsnivå (dvs uppfattade förändringar i den terapeutiska miljön, förändringar i ungdomars beteende och förmågor).

Detta är en samverkande multi-site studie som involverar CSSWP, the JBFCS Westchester facilities, the JBFCS Center for Trauma Program Innovation, the Columbia University School of Social Work och the Columbia University New York State Psychiatric Institute. Forskningsledare för studien är en filial till CSSWP och en fakultetsmedlem vid CUSSW. Medverkande forskare inkluderar medlemmar från var och en av de samarbetande organisationerna. Forskningen finansieras av NIMH (Rivard, 2000).

\section{Två typer av multi-site forskning}


I anslutning till dessa tre typer av multi-site forskning, kan två större typer av multi-site forskning specificeras. De två typerna är: (1) multi-site intervention forskning; (2) multi-site survey forskning. Dessa beskrivs i det följande med exempel på vart och ett.

\section{Multi-site intervention forskning}

I multi-site intervention forskning är målet att studera och dra slutsatser om interventionsprogram. Exempel på multi-site interventionsforskning är de tidigare beskrivna From Research to Practice, the NIMH Treatment of Depression Collaborative Study, Project MATCH, och the Sanctuary studien. Exampel på multi-site survey forskning beskrivs i det följande.

\section{Multi-site survey forskning}

En andra typ av multi-site forskning har som mål att beskriva populationer genom att använda undersökningsmetoder. Både slumpmässigt urval och metoder för icke slumpmässigt urval kan användas. Jag kallar denna andra typ av multi-site forskning för multi-site survey forskning. I undersökande forskning används flera platser för urvalet för att öka representativitet och öka urvalsstorlek. Detta är en väl känd tillämpning av multi-site forskning med väl utvecklade metodologier.

\section{Slumpmässigt urval i multi-site forskning}

Fyra exempel på multi-site survey forskning ges i det följande varav tre använder slumpmässigt urval och ett använder metoden icke slumpmässigt urval. Exempel på såväl enkel som komplex multi-site forskning tillhandahålles. Exemplen inkluderar studier utförda av CSSWP såväl som genom NIMH-finansierad forskning.

En studie av patientprofil 
I multi-site survey forskning kan slumpmässigt urval användas. Slumpmässigt urval har länge använts i undersökande forskning. Dessa urval kan vara geografiska platser. Ett exempel på en sådan multi-site studie är the Patient Profile Study. Detta är en enkel multi-site studie som använder sannolikhetsmetoder. Undersökningen utfördes av CSSWP. De geografiska platser som samplades var ett antal av JBFCS kliniker för mental hälsa som låg i fyra av New Yorks stadsdelar. Forskningens mål var att beskriva populationen patienter, barn och vuxna, som uppsökte dessa kliniker för mental hälsoservice. Ungefär $20 \%$ av klienterna, vuxna och barn, valdes slumpmässigt ut från dessa kliniker och skiktades (??) på bas av klinik, etnicitet och ålder. Likaledes specificerades resultaten enligt plats såväl som enligt etnicitet och ålder. På grund av att multiple sites användes drogs slutsatser både gällande varje klinik och gällande den totala populationen vid JBFCS (Mattaini, Grellong \& Abramovitz, 1992).

En studie av epidemiologiskt upptagningsområde (ECA)

The Epidemiologic Catchment Area Study (ECA) är ett väl känt exempel på multi-site survey forskning. Det var en simple multi-site studie på så sätt att vanliga forskningsfrågor och tillvägagångssätt användes över platser. Studien använde flerstegssannolikhet och hämtade material från fem geografiska platser. Avsikten med ECA-forskningen var att samla data över förekomsten av incidenter av mental störning och över användning och behov av service till mentalt sjuka. Oberoende forskarlag från fem universitet (Yale University, Johns Hopkins University, Washington University, Duke University och University of California at Los Angeles), i samarbete med the National Institute for Mental Health, utförde studier med en kärna av gemensamma frågor och urvalskarakteristika. Platserna var områden som tidigare utsetts som upptagningsområde för Community Mental Health Center. Varje plats samplade över 
3000 kommuninvånare och 500 boende på institutioner, vilket gav hela 20861 svar.

ECA:s longitudinella design innehöll två personliga intervjuer som utfördes med ett års mellanrum och en kortare telefonintervju som genomfördes under mellantiden. Emedan ECA använde slumpmässigt urval inom var och en av fem platser, kan inte dessa platser antas vara representativa för popultionen i USA (Robins \& Regier, 1991). För att ta itu med denna begränsning utfördes sedan en annan NIMH-finansierad studie, the National Co-morbidity Survey (NCS), med slumpmässigt urval från den totala populationen i USA (Kessler, et al., 1994). NCS upprepas för närvarande.

Metoder för "the Epidemiology of Child and Adolescent Mental Disorders Study (MECA)"

Denna NIMH-finansierade studie är ett exempel på en komplex multi-site undersökning som använder slumpmässigt urval. Denna samverkansstudie, MECA, utfördes för att utveckla metoder för att undersöka mentala störningar och utnyttjande av service i icke sorterad populationsbaserad sampling av barn och ungdomar. Ett slumpmässigt urval av ungdomar togs ut vid fyra platser och intervjuer utfördes med totalt 1,285 par, dvs ungdomar tillsammans med vuxen ansvarig i deras hem. Intervjuarna använde sig av en datastödd version av the NIMH Diagnostic Interview Schedule for Children Version 2.3 (DISC) och strukturerade intervjuerna för att bedöma demografiska variabler, funktionsförsämring, riskfaktorer, serviceutnyttjande, och hinder för serviceutnyttjande. Mer är 7,500 hushåll räknades vid fyra platser. Eftersom platserna varierade när det gällde tillvägagångssätt och de forskningsfrågor som undersöktes, kan detta anses som en komplex multi-site undersökning

\section{Icke slumpmässigt urval i multi-site forskning}


Icke-slumpmässigt urval kan också användas för att försöka beskriva en population. Multiple sites fungerar ofta som källa för sådan forskning. Ett exempel från vårt arbete vid CSSWP beskrivs i det följande.

\section{Projektet Odyssey}

Odyssey Projektet är ett exempel på en simple multi-site undersökning som använder metoder för icke-slumpmässigt urval. Odyssey Projektet är en multi-site samarbetsstudie i vilken CSSWP deltar. Odyssey Projektet är en deskriptiv och undersökande studie av barn i institutionsvård, grupphem och terapeutisk fosterhemsvård i USA. The Child Welfare League of America utför tillsammans med stöd från sina medlemmar denna nationella, multi-site, deskriptiva och undersökande studie av barn och ungdomar i vård. Avsikten med den deskriptiva fasen är att fastställa vilken typ av miljö och service som ges till vilka barn och ungdomar. Avsikten med den prospektiva fasen är att fastställa vilken typ av miljö och service som är relaterad till själva utfallet och för vilka barn och ungdomar. Forskningsfrågorna var designade för att undersöka påverkan av gruppvården, grupphem och terapeutisk forsterhemsvård för barn och ungdomar i vård. Barn som påbörjade vården mellan april 1995 och juli 1999 kunde delta i projektet. 28 byråer från 15 stater deltog och ungefär 3100 barn och ungdomar var tillgängliga för sampling. Många av dessa deltagande institutioner inkluderade åtskilliga enheter och antal distinkta platser blev därigenom fler än 28. Följaktligen är flera platser i detta exempel inordnade i byråer som i sin tur är inkapslade inordnade $\mathrm{i}$ den större CWLA-studien.

Ofta refereras till multi-site studier som av naturen varande "kollaborativa". Detta är fallet när det gäller Odyssey Projektet. Som samarbetspartners i forskningen hade medlemsbyråerna klart definierade rättigheter och skyldigheter. 


\section{Frågeställningar i multi-site studier}

För att identifiera problem i multi-site studier har jag hämtat material från åtskilliga källor. Inledningsvis vill jag ge mitt fulla erkännande till dessa källor för den inblick de ger. Jag har noterat den överensstämmelse som funnits i källmaterialet över problem i multi-site forskning. Elkin's paper presenterar hennes personliga reflektioner från erfarenheter av det tidigare beskrivna programmet NIMH Treatment of Depression Collaborative Research Program (Elkin, 1992). De dokument som författats av medlemmarna i forskarlaget i det tidigare beskrivna projektet Project MATCH identifierar problem med kontext i multi-site studie (Carrol et al., 1998; Del Boca et al., 1994; Fuller et al., 1994; Zweben et al., 1994). Observationerna av det tidigare beskrivna UNOCCAP Oversight Board baseras på en noggrann genomgång av tidiga erfarenheter från det forskningsprogrammet (National Institute of Mental Health, 1998). Slutligen har jag i min egenskap av ledare för CSSWP hämtat information från mina egna erfarenheter med de många muli-site studier som utförts av CSSWP (Practice \& Research, våren 2000). Med hänsyn till det begränsade utrymme som ges här kommer jag endast att ge ett sammandrag.

\section{Fördelar med Multi-site forskning}

Fördelarna med multi-site forskning är tydliga och har redan nämnts. Möjligheten att hämta subjekt från multiple sites kan öka samplingsmängden. Likaledes ökas en studies statistiska kraft. Multiple sites kan dessutom öka skillnaderna i de variabler som är intressanta i samplingen. En ytterligare fördel med multi-site forskning hänför sig till reproduktion. Med rätt utförande kan multi-site forskning ge en simultan replikation med antal jämförbara platser i studien som enda begränsning. Till desa 
fördelar lägger Elkin ytterligare två. En gäller möjligheten till ökade resurser, både när det gäller finansiering och expertis. Tillgången till multi-site team-medlemmar med metodologisk, statistisk och klinisk expertkunskap kan bli ovärderlig. Knutet till detta är även fördelarna med gemensamt beslutsfattande, som resulterar i berikande diskussioner och förbättrade resultat. Som noterat av Fuller et al (1994), finns även möjligheten i multi-site forskning att skapa en centraliserad enhet med resurser för kärnfunktioner såsom dataanalys.

\section{Nackdelar med Multi-site forskning}

Om utförandet brister öppnar detta för möjliga nackdelar i samband med multisite forskning. Elkin (1997, 1994), Fuller, et al (1994), Del Boca et al. (1994) och Zweben et al. (1994) beskriver eventuella nackdelar:

- Multi-site studier kan bli kostsamma och metodologiskt komplexa.

- Processen med gemensamt bestlutsfattande, procedurmässiga hänsyn och hänsyn till metodologiska problem och gemensam lösning av dessa problem, kräver en omfattande tid och stor ansträngning.

- Skillnader mellan de olika platserna kan skapa problem vid gemensam databehandling, analys och tolkning.

- Det kan uppstå svårigheter i planläggning och utförande när implementationen spänner över ett flertal platser. Exemplen inkluderar placering av personal vid olika platser, kommunikation mellan genografiskt skilda medlemmar och liknande. 
- Statistiska frågor kan skapa problem såsom hur man bäst skall kombinera data som insamlats från olika platser. Påverkanseffekt av olika platser behöver behandlas i den statistiska analysen.

- Att ta hänsyn till nya krav och frågor efter att studien har inletts kan vara problematiskt. Platserna kan till exempel genomgå förändringar i policy och budget som kan ha betydelse för studien och som därför kräver justeringar av tillvägagångssättet. När det rör sig om många platser kan sådana förändringar vara svåra att följa upp, rent tidsmässigt, på ett lämpligt sätt.

- Frågor som rör pålitligheten av datainsamling över platserna är ofta problematiska. Platserna kan implementera datainsamling på olika sätt och därigenom skapas svårigheter att behålla ett likvärdigt tillvägagångssätt.

- Frågor angående rekrytering av subjekt och urvalskriterier kan vara komplex när det gäller multi-site studier. Dessa frågor kan uppstå till följd av bristande likheter mellan platserna och även till följd av svårigheter i planläggning och utförande av den uppföljning som kan behöva göras av de olika tillvägagångssätt, som kan finnas vid de olika platserna.

- Ett överflöd av personal över platserna kan skapa onödiga kostnader. Noggrann planering behövs för att försäkra sig om en effektiv användning av personalen på de olika platserna.

- Det kan finnas problem med att etablera och bibehålla samarbete och engagemang över platserna eftersom ingen enskild plats "äger" eller är totalt 
ansvarig för forskningen. Följaktligen är det så att i många multi-site studier har enskilda platser sin begränsade del och åtnjuter ett begränsat erkännande.

- Multi-site studier får ofta problem att uppehålla likhet i tillvägagångssätt över samtliga platser. Att upprätthålla överensstämmelse vid platserna kan vara problematiskt (t.ex. likheter i implementation över platserna, datainsamling etc). Det uppstår också större svårigheter att bibehålla integritet i behandling och forskning över platser när det gäller ett flertal sådana.

- Det behöver upprättas mekanismer för hur data skall analyseras och publiceras med skydd för den individuella platsen likaväl som totalt för hela insatsen.

\section{Summering och slutsatser}

Denna artikel har undersökt multi-site forskning, som är tillämplig av skäl som skiljer den från single site forskning. I denna artikel har jag undersökt former och typer av multi-site forskning för att illustrera varierande tillämpningar. Jag har beskrivit några exempel av multi-site forskning på nationell nivå med referens till mental hälsoservice och behandling av alkoholberoende. Från min erfarenhet som ledare för ett center för forskning i socialt arbete har jag beskrivit ytterligare tillämpningar i metalhälsaoservice, barnavård och praktisk socialt arbete. Jag har beskrivit några fördelar och nackdelar av multi-site forskning. I sammanfattningen av denna analys ger jag förslag till de som överväger deltagande i multi-site forskning. Emedan det finns många saker att ta hänsyn till har jag begränsat mina kommentarer i denna sammanfattande del till tre områden, som jag anser vara de som oftast är de mest försummade men som är speciellt viktiga för en lyckad multi-site forskning. Eftersom multi-site forskning kan vara dyr och involvera 
relativt fler resurser och mer tid än single-site forskning, borde den inte påbörjas om inte alla förhandsvillkor är uppfyllda. Flera av dessa förhandsvilkor beskrivs i det följande.

\section{Begrepp och metoder som tidigare utvecklats och testats}

Ett viktigt förhandsvillkor är att preliminära studier skall ha visat att nyckelfrågorna är begreppsmässigt riktiga och att forskningsmetoderna för att undersöka dessa frågor har blivit tillräckligt utvecklade. Så var det till exempel med det ambitiösa forskningsprogrammet UNOCCAP som antogs efter omfattande metodologiskt arbete i den studie som beskrivits ovan, $M E C A$-studien. Hursomhelst blev forskningsprogrammet $U N O C C A P$ stoppat av NIMH därför att det blev fastställt att de mål och forskningsfrågor som ursprungligen uppställts av UNOCCAP, var för breda, ojämnt utvecklade och för omfattande. The NIMH Review Board sammanfattade enligt följande:

--- ingen enskild studie kan samtidigt behandla var och en av dessa frågor. Det finns ingen möjlighet att kombinera dessa frågor med en metod eller design utan att offra kvaliteteten på data. --- Vissa områden kräver ytterligare utarbetande, bättre instrument eller mer empiriskt arbete för att kunna generera eller testa hypoteser. Denna kritiska basforskning måste utföras för att lägga grunden till besvarandet av alla dessa frågor. --- Ännu viktigare är att vetenskapen ännu inte är mogen för ett sådant tillvägagångssätt. Enkelt förhåller det sig så att ett nödvändigt ytterligare utarbetande, verktyg och design, inte enhetligt finns att tillgå i alla de faktiska områdena. Om resurserna riktades till en prematur igångsättning av ett sådant omfattande och komplicerat försök, fruktar styrelsen att det skulle generera data som ej var användbara för beslutsfattarna, och som en stor del av forskarna inte godtog som tillförlitliga." (National Institute of Mental Health, 1998, 24)

Till denna läxa från erfarenheterna från UNOCCAP kan läggas vad som

framkommit i ovan beskrivna studie From Research to Practice. I den studien upplevdes ovanliga problem med att säkra platsernas samarbete och även med att engagera 
tillräckligt antal kliniker och patienter. Trots att man under planeringsstadiet fått stöd från platsens centrala administration, så uppstod problem på lokal nivå som hänförde sig till motivation och engagemang när det gällde genomförandet av studien. Det var också så att medan preliminär analys visade att platserna hade tillräckligt antal medlemmar kliniker och klienter, så var det under själva implementeringen svårt att engagera det nödvändiga antalet av båda. I detta exempel skulle man kunna säga att en multi-site studie var prematur. Istället borde kanske pilotförsök och test av forskningsmetodologi ha föregått en sådan ambitiös multi-site undersökning.

\section{Resurser på plats}

Ett andra förhandsvillkor för multi-site forskning är att nödvändiga resurser måste säkerställas innan multi-site studier inleds. Multi-site studier fordrar lämpliga resurser för att stödja en central kärnfunktion likaväl som att stödja platsspecifika aktiviteter. Den centrala kärnfunktionen kan handha vanliga funktioner såsom databearbetning och därigenom avlasta platserna. Ekonomiskt stöd och lämplig personal fordras för att säkerställa att alla program och forskningsfunktioner blir ordentligt implementerade under hela studiens livslängd. Emellertid förbises ofta detta i planeringen av multi-site studier och det gäller både ekonomiska resurser och kvalificerad arbetskraft för den del som här kallas "relationship" i multi-site forskning. Kontinuerlig och tät kommunikation bland alla inblandade parter är utomordentligt viktig för engagemang, motivation och ventilering av dagliga problem. Medan detta är en nödvändighet i single-site forskning är denna aspekt livsviktig i multi-site forskning (Mullen, 1998).

\section{Klargörande av ledning och överenskommelse mellan parterna}


Ett tredje förhandsvillkor är att en klart definierad och överenskommen ledningsoch förvaltningsstruktur samt att ett tillvägagångssätt har utvecklas före implementation av multi-site forskning. På grund av sådana studiers komplexitet och ovanliga “ownership” karaktär, , skall regler och tillvägagångssätt vara klara från början. Differentiella ansvarsförhållande hos det centrala koordinationsteamet, platsteamen, praktiker och forskare, programadministratörer, finansiärer, och andra samarbetsparter måste vara specificerade och överenskomna. Eftersom det finns olika ledningsmodeller måste man överväga vilken modell som bäst passar omständigheterna för en given multi-site studie.

Om dessa och andra förhållanden är uppfyllda skall multi-site forskning övervägas om det är fastställt att single-site forskning inte kan ge en tillräcklig samplingsmängd, önskad heterogenitet, eller en tillräcklig bas för att kunna dra slutsatser gällande en population. Multi-site forskning skall också övervägas när man önskar uppnå en löpande reproduktion. Som diskuteras av Boruch, et al. på annan plats i denna tidskrift skall allocation multi-site forskning övervägas när geografiska platser eller andra komplexa enheter är de enheter som skall studeras.

Slutligen bör framhållas att för att uppnå framgång och utveckling av framtida generationer multi-site forskning är det viktigt att få fram gedigen och detaljerad litteratur angående planering, implementering, analys och avrapportering av multi-site forskning. Forskare som är involverade i multi-site studier behöver ta ansvar för att bidra till denna litteratur genom att rapportera inte enbart multi-site resultat utan också vad de lärt under multi-site forskningens gång. Med undantag för översiktsforskning har lite 
skrivits om metodologier i multi-site forskning och dess applikation i sociala interventioner.

\section{Referenser}

Allen, J., Anton, R.F., Babor, T.F., Carbonari, J., Carroll, K.M., Connors, G.J., Cooney, N.L., Del Boca, F.K., DiClemente, C.C., Donovan, D., Kadden, R.M., Litt, M., Longabaugh, R., Mattson, M., Miller, W.R., Randall, C.L., Rounsaville, B.J., Rychtarik, R.G., Stout, R.L., Tonigan, J.S., Wirtz, P.W., \& Zweben, A. (1998). Matching alcoholism treatments to client heterogeneity: Project MATCH three-year drinking outcomes. Alcohol Clin Exp Res, 22 (6): 1300-1311 Sep 1998.

Allen, J.P., Mattson, M.E., Miller, W.R., Tonigan, J.S., Connors, G.J., Rychtarik, R.G., Randall, C.L., Anton, R.F., Kadden, R.M., Litt, M., Cooney, N.L., DiClemente, C.C., Carbonari, J., Zweben, A., Longabaugh, R.H., Stout, R.L., Donovan, D., Babor, T.F., Del Boca, F.K., Rounsaville, B.J., Carroll, K.M., Wirtz, P.W., Bailey, S., Brady, K., Cisler, R., Hester, R.K., Kivlahan, D.R., Nirenberg, T.D., Pate, L.A., Sturgis, E., Muenz, L., Cushman, P., Finney, J., Hingson, R., Klett, J., \& Townsend, M. (1997). Matching alcoholism treatments to client heterogeneity: Project MATCH posttreatment drinking outcomes. Journal of Studies on Alcohol, 58 (1): 7-29 Jan 1997.

American Psychiatric Association (1994). Diagnostic and statistical manual of mental disorders. Washington, DC: Author.

Anon (1998). Matching alcoholism treatments to client heterogeneity: Treatment main effects and matching effects on drinking during treatment. J Stud Alcohol, 59 (6): 631639 Nov 1998.

Bacon, W.F. (2000). From research to practice: The C-DISC in clinical services. Practice \& Research, Spring 2000, 26-28.

Blazer, D., D. Huges, \& George, L.K. (1987). The epidemiology of depression in an elderly community. The Gerontologist: 27 (1987), 281-287.

Boruch, R. \& Foley, E. (2000). The honestly experimental society: Sites and other entities as the units of allocation and analysis in randomized trials. In Bickman, L. (ed.). Validity and social experimentation: Donald T. Campbell's legacy. Thousand Oaks, Ca: Sage pp 193-238.

Carroll, K.M., Connors, G.J., Cooney, N.L., DiClemente, C.C., Donovan, D.M., Kadden, R.R., Longabaugh, R.L., Rounsaville, B.J., Wirtz, P.W., \& Zweben, A. (1998). Internal validity of project MATCH treatments: Discriminability and integrity. Journal of Consulting and Clinical Psychology: 66 (2): 290-303 Apr 1998.

Del Boca, F.K., Babor, T.F., McRee, B., (1994). Reliabiltiy enhancement and estimation in multi-site clinical-trials. J Stud Alcohol: 130-136 Suppl. 12 Dec 1994. 
Eaton, W.W., et al. (1985). The epidemiologic catchment area program of the National Institute of Mental Health. Public Health Reports: 96 (1981), 319-325.

Eaton, W.W., \& Kessler, L. (eds) (1985). Epidemiology field methods in psychiatry: The NIMH epidemiologic catchment area program. Orlando, FL: Academic Press, Inc., 1985.

Elkin, I. (1992). Multi-site studies: Advantages and disadvantages. In Gerin, P \& Dazord, A., Recherches Cliniques "Planifees" sur Les Psychotherapies: Methodolgie. Paris: INSERM, 1992.

Elkin, I. (1994). The NIMH treatment of depression collaborative research program: Where we began and where we are. In Bergin, A.E. \& Garfield, S.L., Handbook of psychotherapy and behavior change. New York: John Wiley and Sons, Inc.

Fuller, R.K., Mattson, M.E., Allen, J.P., Randal, C.L. Anton, R.F. \& Babor, T.F. (1994). Multi-site clinical-trials in alcoholism-treatment research - organizational, methodological and management issues. J Stud Alcohol: 30-37 Suppl. 12 Dec 1994 .

Guterman, N.B. (2000). The Odyssey project and community violence exposure among children \& youth living in residential treatment settings. Practice \& Research, Spring 2000, 23-25.

Journal of the American Academy of Child and Adolescent Psychiatry (1996). Special Section on Epidemiology of Child and Adolescent Mental Disorders. 35:7.

Kessler, R.C., McGonagle, K.A., Zhoa, S., Nelson, C.B., Hughes, M., Eshleman, S., Wittchen, H. \& Kendler, K.S. (1994). Lifetime and 12-month prevalence of DSM-III-R psychiatric disorders in the United States. Archives of General Psychiatry, 51, 8-19.

Lahey, B.B., Flagg, E.W., Bird, H.R., Schwab-Stone, M.E., Canino, G., Dulcan, M.K., Leaf, P.J., Davies, M., Brogan, D., Bourdon, K., Horwitz, S.M., Rubio Stipec, M., Freeman, D.H., Lichtman, J.H., Shaffer, D., Goodman, S.H., Narrow ,W.E., Weissman, M.M., Kandel, D.B., Jensen, P.S., Richters, J.E., \& Regier, D.A. (1996). The NIMH Methods for the Epidemiology of Child and Adolescent Mental Disorders (MECA) study: Background and methodology. Journal of the American Academy of Child and Adolescent Psychiatry: 35 (7): 855-864 Jul 1996.

Mattaini, M. A., Grellong, B. A., \& Abramovitz, R. (1992). The Clientele of a Child and Family Mental-Health Agency - Empirically Derived Household Clusters and Practice Implications. Research on Social Work Practice, 2(3), 380-404.

Mullen, E.J. (in preparation). From research to practice: A preliminary report of the CDISC on dimensions of clinician, patient and caretaker satisfaction (presented as an unpublished paper under title of: "Using assessment instruments in social work practice". October 7-8, 1999, Inter-Centre Consortium of Social Work Research Centers, 
Stockholm, Sweden). In preparation as an on-line electronic pre-print to be available: London, UK: National Institute for Social Work, http://www.intsoceval.net/Stockholm/stockholmpapers.htm .

Mullen, E.J. (2001). Outcome measurement in social work: health and mental health. (plenary session, 3rd International Conference on Social Work in Health and Mental Health, July 1-5, 2001, Tampere, Finland; [On-line electronic pre-print]. Available: London, UK: National Institute for Social Work, http://www.intsoceval.net/Utrecht/utrechtpapers.htm.

Mullen, E.J. (1998). Linking the university and the social agency in collaborative evaluation research: Principles and examples. Scandinavian Journal of Social Welfare. nr2.

Mullen, E.J. and Magnabosco, J. (eds) (1997). Outcomes measurement in the human services. Washington:D.C.: National Association of Social Workers.

National Institute of Mental Health (1994). Multi-site study of mental health service use, need, outcmes, and costs in child and adolescent populations. NIH Guide: vol 23, number 15, April 15, 1994 RFA.

National Institute of Mental Health (1998): Report from the UNOCCAP oversight board to the National Advisory Mental Health Council: Charting the mental health status and service needs of children: Recommendations from the UNOCCAP oversight board.

Practice \& Research: Journal of the Center for the Study of Social Work Practice (Spring 2000).

Project MATCH Research Group (1997). Matching alcoholism treatments to client heterogeneity: Project MATCH posttreatment drinking outcomes. Journal of Studies on Alcohol 58:1, 7-29. (also see:, Journal of Studies on Alcohol, Supplement No. 12, December 1994.)

Regier, D. A. (1994). ECA contributions to national policy and further research. International Journal of Methods in Psychiatric Research. 4, 73-80.

Rivard, J.C. (2000).Evaluating the implementation and impact of an intervention designed to enhance residential treatment for adolescents with histories of trauma. Practice \& Research, Spring 2000, 33-36.

Robins, L. N., \& Regier, D. A. (Eds.) (1991). Psychiatric disorders in America: The Epidemiologic Catchment Area Study. New York: The Free Press.

Zweben, A., Donovan, D.M., Randall, C.L., et al. (1994). Issues in the development of subject recruitment strategies and eligibility criteria in multi-site trials of matching. $\mathrm{J}$ Stud Alcohol: 62-69 Suppl. 12 DEC 1994. 
${ }^{\mathrm{i}}$ The term "research" is used and it is meant to include both "program evaluation" as well as other forms of intervention and survey research.

${ }^{\text {ii }}$ As Director of the Center for the Study of Social Work Practice I have had the opportunity to observe a wide range of multi-site research applications in social welfare. The Center has lent itself to multi-site research because of its organizational sponsorship as well as its mission. The Center is located at Columbia University in the City of New York. It is a joint program of the Columbia University School of Social Work (CUSSW) and the New York City based Jewish Board of Family and Children's Services (JBFCS). Research studies have been conducted by principal investigators who are faculty members at the university. Accordingly, their interests have been national and international in scope supporting studies located at sites in New York City as well as in other locations throughout the United States and to some extent in other countries. Because of the Center's affiliation with the JBFCS the Center has tended to carry out research at locations served by that agency's programs, oftentimes through multi-site research projects. Indeed, the population served by JBFCS and, therefore, the focus of the Center's work is comparable in size and diversity with that of many national service organizations in other countries. The agency has a target population of over eight million New York residents spread over five boroughs. Over the period of one-hundred years the JBFCS has grown into one of the United States' largest nonprofit mental health and social service agencies. Now, JBFCS is a comprehensive agency that serves over 54,000 New Yorkers annually from all religious, ethnic, and economic backgrounds through 140 community-based programs, clinics, residential facilities, and day-treatment centers. JBFCS employs 1,400 staff including professional social workers, licensed psychologists, and psychiatrists, as well as a cadre of clinical support personnel in continuing day treatment and residential treatment centers. In addition services are provided by approximately 1,700 volunteers. Many of the Center's studies have been carried out at one or more of the ten JBFCS' New York State licensed outpatient mental health clinics, which provide mental health services for a wide range of emotional and social problems. Services for adults and children include evaluation and assessment; crisis intervention; and time-limited, timeeffective, and ongoing individual, couple, family, and group therapy.

iii This is often the case for evaluation and intervention research studies. However, survey research studies often include large samples.

${ }^{\text {iv }}$ Statistical power is necessary to detect hypothesized associations between variables when using inferential statistical methods.

${ }^{\mathrm{v}}$ This report is based on research conducted under subcontract to the Center for the Study of Social Work Practice - CSSWP (New York State Research Foundation for Mental Hygiene contract \#SDMHCU00642601). The multi-site study was initially funded by the National Institute of Mental Health Grant \#1R01MH052822-01 (02) (03). The Principal Investigator at the New York State Psychiatric Institute was David Shaffer, M.D. and the Co-Investigators were Prudence Fisher, Ph.D. and Christopher Lucas, M.D. The investigators for the Center for the Study of Social Work Practice subcontract were: Principal Investigator Edward J. Mullen, D.S.W.; Co-Investigators Robert Abramovitz, M.D., William Bacon, Ph.D. and Bruce Grellong, Ph.D. Prior investigators included Helene Jackson, Ph.D. and Jennifer Magnabosco, Ph.D. 